\title{
Caveolae and Cancer: A New Mechanical Perspective
}

\author{
Christophe Lamaze ${ }^{1,2,3}$, Stéphanie Torrino ${ }^{1,2,3}$
}

Caveolae are small invaginations of the plasma membrane in cells. In addition to their classically described functions in cell signaling and membrane trafficking, it was recently shown that caveolae act also as plasma membrane sensors that respond immediately to acute mechanical stresses. Caveolin 1 (Cav1), the main component of caveolae, is a multifunctional scaffolding protein that can remodel the extracellular environment. Caveolae dysfunction, due to mutations in caveolins, has been linked to several human diseases called "caveolinopathies," including muscular dystrophies, cardiac disease, infection, osteoporosis, and cancer. The role of caveolae and/or Cav1 remains controversial particularly in tumor progression. Cav1 function has been associated with several steps of cancerogenesis such as tumor growth, cell migration, metastasis, and angiogenesis, yet it was observed that Cav1 could affect these steps in a positive or negative manner. Here, we discuss the possible function of

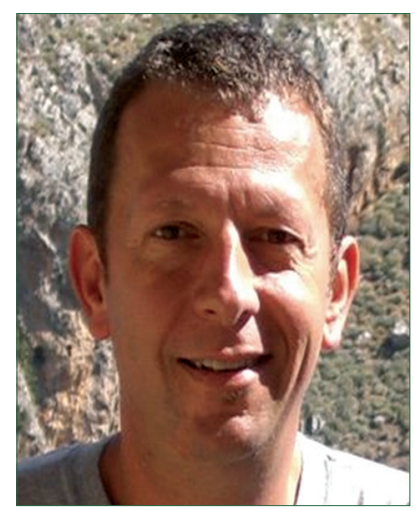

Dr. Christophe Lamaze caveolae and Cav1 in tumor progression in the context of their recently discovered role in cell mechanics. (Biomed J 2015;38:367-379)

\section{Key words: cancer, caveolae, caveolin, cavin, mechanics}

$\mathrm{C}$ aveolae (for "little caves") are small (50-100 nm) plasma membrane invaginations discovered by electron microscopy in 1953. ${ }^{[1]}$ Caveolin (Cav) and Cavin proteins are the key components of caveolae that are enriched in glycosphingolipids, cholesterol. Cav1 was identified in a screen of proteins phosphorylated by the tyrosine kinase $\mathrm{v}-\mathrm{Src}^{[2,3]}$ and the same year Vesicular Integral-membrane Protein of $21 \mathrm{kDa}$ (VIP21) was found to be Cav1. VIP21 was cloned as a component of the vesicular transport machinery localized at the plasma membrane, the Golgi network and on vesicular structures..$^{[4,5]}$ Among the three caveolin isoforms, Cav1 and Cav3 but not Cav2 are required for caveolae biogenesis. Cav3 expression is restricted to muscle.

Caveolins have long been known to interact with a variety of signaling molecules, which include G-protein coupled receptors, Src family kinases, ion channels, endothelial nitric oxide synthase (eNOS), adenylyl cyclases, protein kinase A (PKA), and mitogen-activated PKs (MAPKs). ${ }^{[6,7]}$ There is, however, some debate on the relevance of these interactions and the mechanisms by which caveolae and/or caveolins may control intracellular signaling. ${ }^{[8]}$

The modulation of cell signaling by caveolae and/or Cav1 could be one of the mechanisms by which caveolae play a role in cell transformation and tumor progression. In humans Cav1 is localized to the locus D7S522 of 7q31.1 chromosome, often deleted in cancers, ${ }^{[9]}$ suggesting a tumor suppressor role. However, others studies have also shown that Cav1 expression is up-regulated in cancers, suggesting instead an oncogenic activity. These data and others ${ }^{[10]}$ indeed emphasize the existing controversy on the role of Cav1 and caveolae in cancer and the need to obtain more mechanistic insight on Cav1 function. In this review, we will try to resume the roles of Cav1 in tumorigenesis and to address this apparent controversy in the light of our recent results on caveolae in cell mechanics. ${ }^{[8,11]}$

\section{Functions of caveolin-1}

\section{Caveolin-1 structure}

After the initial discovery of caveolae, it took almost 40 years to identify Cav1, its main constituent. ${ }^{[12]}$ Cav1 is a

From the ${ }^{1}$ Institut Curie-Centre de Recherche, PSL Research University, Membrane Dynamics and Mechanics of Intracellular Signaling Laboratory, Paris, France; ${ }^{2}$ National Institute of Health and Medical Research (INSERM) U1143, Paris, France; ${ }^{3}$ Centre National de la Recherche Scientifique, UMR 3666, Paris, France

Received: Feb. 06, 2015; Accepted: Aug. 17, 2015

Correspondence to: Dr. Christophe Lamaze, Institut Curie-Centre de Recherche, Membrane Dynamics and Mechanics of Intracellular Signaling Laboratory, Paris, France. 26 rue D’Ulm, F-75248 Paris, France. Tel.: 33-1-56246966; Fax: 31-1-56246507;

E-mail: christophe.lamaze@curie.fr

DOI: $10.4103 / 2319-4170.164229$ 
membrane 178 amino acids protein of $21 \mathrm{kDa}$, synthesized in the endoplasmic reticulum and assembled along the membranes of the secretory pathway into large caveolar domains. Cav1 has a high affinity for cholestero ${ }^{[13]}$ and forms oligomers. ${ }^{[14]} \mathrm{Cav} 1$ oligomerization is key to the generation of the final caveolae structure, each of which contains approximately 150 Cav 1 molecules. ${ }^{[15-18]}$

The Src tyrosine kinase can phosphorylate Cav1 on its tyrosine 14 residue, a post- translational modification that has been associated with different processes including cell migration, signal transduction, and focal adhesion dynamics. ${ }^{[19,20]}$ In vivo, two isoforms of Cav1 were observed: $\alpha$-Cav 1 that contains residues $1-178$ and $\beta$-Cav1 that contains residues $32-178$. Thus, only $\alpha$-Cav 1 can be phosphorylated by the Src kinase. Recently, other tyrosine kinases such as c-Abl and Fyn were identified as able to phosphorylate Cav1 on tyrosine 14 as well. ${ }^{[10]} \mathrm{Cav} 1$ can also be phosphorylated on its serine 80 residue, a modification that has been linked to Cav1 secretion. ${ }^{[1-23]}$

It has been difficult to translate the apparent diversity of Cav1 interacting molecules into a consensus binding sequence within Cav1. Several studies have, however, outlined the presence of a Cav1 binding motif (CBM) in several signaling proteins. ${ }^{[24-26]}$ The CBM would allow the interaction with a so-called Cav-scaffolding domain (CSD), a conserved region (residues 82-101) within the Cav1 domain that lies in the vicinity of the plasma membrane. As indicated by its name, the CSD is required for the oligomerization of Cav1 and binds cholesterol. The Cav1 CSD would bind several signaling effectors including some growth factors receptors, eNOS, Src tyrosine kinases, G-proteins and G-proteins coupled receptors. ${ }^{[8]}$ This hypothesis has been, however, recently debated based on the structural analysis of the known CBM motifs. ${ }^{[27]}$ Nevertheless, it was shown that CSD mimetic peptides can modulate eNOS activity in endothelial cells. ${ }^{[28]}$ Clearly, the ability of Cav1 to bind and modulate different signaling effectors through its CSD may have an important role in tumor progression. Further studies are, however, needed to understand the role of the CSD domain in caveolae function.

\section{The caveolae structure}

Despite their close morphological resemblance with clathrin-coated pits, the role of caveolae in endocytosis appears to be quantitatively minor. ${ }^{[29]}$ In fact, caveolae are stably anchored at the plasma membrane through interactions with the actin cytoskeleton and actin connectors such as filamin A and the adenosine triphosphatase (ATPase) Eps-15 homology domain-containing protein 2 (EHD2) ${ }^{[30,31]}$ Indeed, in cells devoid of Cav1 or depleted for Cav1, no caveolae invaginations can be morphologically detected at the plasma membrane. ${ }^{[32]}$ Recently, cavins, a new family of cytosolic proteins have been identified as important structural ele- ments of caveolae. Cavins present a coiled-coil domain in the amino-terminal part allowing the formation of large heteromeric complexes that are recruited to caveolae at the plasma membrane. ${ }^{[16,33,34]}$ Four cavins have been identified in mammals: Cavin1 (also known as PTRF for Polymerase I and transcript release factor), Cavin2 (also known as SPDR for serum deprivation response protein), Cavin3 (also known as SRBC for sdr-related gene product that binds to c-kinase) and Cavin4 (also known as MURC for muscle-restricted coiled-coil protein). ${ }^{[35]}$ Cavin1 was identified as a soluble transcriptional factor that facilitates the reinitiation of RNA Polymerase I. ${ }^{[36]}$ It was recently shown that Cavin1 is recruited to the plasma membrane by caveolins and is required for caveolae formation. ${ }^{[37,38]}$ The profile of Cavin1 expression is quite broad and similar to Cav1. The absence of Cavin1 leads to the loss of morphological caveolae and inhibits the expression of caveolae proteins. The inhibition of Cavin 1 only induced an increase of mobility, internalization and degradation of Cav1. ${ }^{[38]}$ Cavin2 was purified as a phosphatidylserine (PS)-binding protein and its messenger RNA (mRNA) is increased in a serum-deprived microenvironment. ${ }^{[39,40]}$ Cavin2 is localized in the caveolae and binds PKC alpha. ${ }^{[4]]}$ The downregulation of Cavin2 induced the loss of Cav1 and Cavin1 expression and limited caveolae formation. ${ }^{[42]}$ Cavin2 was shown to promote recruitment of Cavin1 to caveolae. Cavin3 was identified as a PKCdelta binding protein in a screen ${ }^{[43]}$ Similar to Cavin2, the mRNA for Cavin3 is induced in response to serum deprivation. ${ }^{[43,44]}$ Cavin 3 is highly localized to caveolae and in the absence of Cavin3, Cav1 trafficking is impaired. ${ }^{[45]}$ Cavin 4 is a cytosolic muscle specific protein and can interact with Cavin2. ${ }^{[46]}$ Cavin 4 was shown to influence cardiac function by activating RhoA and extracellular-signal-regulated kinase (ERK) pathway. ${ }^{[47]}$ Cavin 4 is likely to be an interesting candidate for the muscle-related caveolinopathies. Indeed, Cavin4 mutations have recently been linked to human cardiopathies. ${ }^{[48,49]}$

Recent structural studies based on electron microscopy and X-ray crystallography confirm that Cavins together with Cav1 are organizing a caveolar coat that plays an essential role in caveolae assembly. ${ }^{[16-18]}$ Thus, it was shown that Cavin 1 associated with Cavin 2 or Cavin 3 in a mutually exclusive manner at a ratio of 2 or 3 to 1 whereas Cavin 1 associated with Cav1 at a 1-4 ratio. These studies further suggest that cytosolic Cavins oligomers are recruited at the plasma membrane to negatively charged lipids such as phosphatidylinositol $(4,5)$ bisphosphate and PS after their clustering by Cav1. Fifty Cavin and 150 Cav 1 molecules would be present in caveolae and their structural organization would be responsible for the striated aspect of caveolae observed by EM..$^{[18]}$

Pacsin2/syndapin-II (PKC and casein kinase substrate in neurons 2) and EHD2 proteins have also been recently 
identified as new caveolar proteins. Pacsin 2 contains a membrane curvature binding BAR domain, colocalizes partially with caveolae and participates in their morphogenesis. Depletion of Pacsin2 induces a loss of caveolae morphology and a decrease of Cav1 and Cavin1 levels. ${ }^{[31]}$ EHD2 is an ATPase, present at the neck of caveolae. ${ }^{[50-52]}$ EHD2 is not required for caveolae formation but stabilizes the caveolae at the plasma membrane. EHD2 depletion results in increased Cav mobility and caveolae endocytosis. ${ }^{[53]} \mathrm{A}$ three-dimensional electron microscopy analysis has also revealed complex interactions between caveolae and the cytoskeleton. ${ }^{[54]}$ Actin filaments, microtubules and, in particular, contexts, intermediate filaments can all associate with caveolae ${ }^{[30,55,56]}$ These interactions are likely to occur through several proteins reported to bind actin and Cav1 such as Filamin A, EHD2, Pacsin2. ${ }^{[30,31]}$ Caveolae have long been involved in intracellular signaling by organizing specific signaling platforms at the plasma membrane. ${ }^{[57]}$ In agreement with their recently discovered role in cell mechanics, caveolae have also been associated with several bona fide mechano signaling pathways such as MAPK, AKT/PKB, Src Kinases, Rho, and Rac1 GTPases ${ }^{[58]}$ Caveolae may play a direct role in regulating or facilitating lipid and fatty acid transport. ${ }^{[59]}$ In this context, it is interesting that a Cav1 codon stop mutation that results in complete lack of caveolae in a human patient was associated with a major lipodystrophy phenotype. ${ }^{[60]}$

\section{Noncaveolar caveolin-1?}

A relevant and unanswered question is whether caveolae functions are mediated by Cav1 organized as a coat on caveolae or whether noncaveolar Cav1 may also carry distinct activities. ${ }^{[8]}$ Indeed, many studies have attempted to assign a specific function to noncaveolar Cav1 in the regulation of various cellular activities, including lipid transport, gene expression, and mitochondrial function. ${ }^{[61]} \mathrm{Cav} 1$ has been detected in the noncaveolar regions such as the cytoplasm, focal adhesions, and the nucleus. For example, tyrosine phosphorylated Cav1 (pY14) has been localized in focal adhesions and involved in their regulation and stability and regulation of focal adhesion. ${ }^{[62]}$ Indeed, p-Cav1 can stabilize focal adhesion kinase and induce focal adhesion turnover and cell migration. ${ }^{[63]}$ However, the localization of $\mathrm{p}$-Cav1 in the focal adhesion has been put under doubt as it was later observed that the antibody against p-Cav1 recognizes also paxillin. ${ }^{[64]}$

In theory, three distinct Cav1 assemblies could be organized at the plasma membrane: Oligomerized caveolar Cav1, noncaveolar Cav1 scaffolds, and single Cav1. Proteomics and subdiffraction-limit microscopy recently confirmed that Cav1 scaffolds are structurally and functionally distinct from caveolae. ${ }^{[65]}$ Exogenous expression of Cav1 at levels below the threshold for caveolae formation resulted in the assembly of stable oligomerized Cav1 microdomains or scaffolds that can modify lipid ordering and raft dynamics and results in negative regulation of epidermal growth factor receptor signaling by decreasing its diffusion rate. ${ }^{[66]}$

In most studies however, the role of noncaveolar Cav1 has been addressed through experimental conditions where Cav1 levels were artificially increased by transient overexpression or in more recent examples, by knocking down Cavin1 to prevent caveolae assembly. ${ }^{[67]}$ Whether free Cav1 exists at the plasma membrane in addition to caveolae in cells expressing normal levels of cavin and Cav1 remains to be documented.

\section{A new role for caveolae in cell mechanics}

Recently, a new role of the caveolae was established in cell mechanosensing. Under acute mechanical stress induced either by hypo-osmotic swelling or by uniaxial cell stretching, it was observed that caveolae disappear rapidly by flattening out into the plasma membrane ${ }^{[8,11]}$ The caveolae structure provides, therefore, a membrane reservoir, immediately available to buffer against instantaneous changes of membrane tensions in a passive process that does not require ATP. Caveolae flattening is followed by caveolae disassembly as shown by the release of Cav1 and Cavin1 at the plasma membrane. ${ }^{[11,68]}$ It is, therefore, likely that in addition to buffering membrane tension variations, caveolae disassembly will also affect the classical functions mediated by caveolae/Cav1 such as lipid metabolism and intracellular signaling. For instance, the release of Cav1 within the inner leaflet of the plasma membrane could interfere with membrane lipid ordering and Cav1-interacting signaling proteins. Similarly, Cavins that are released in the cytosol may also interfere with caveolae assembly and reassembly upon stress release. Owed to its initial characterization as a transcription factor, the release of cavin1 from caveolae at the plasma membrane could regulate the transcription of various genes upon its nuclear translocation. It will be important to determine, which components of the caveolae-dependent signaling pathways are triggered by mechanical forces at the plasma membrane. On return to normal conditions, there is an immediate reassembly of the caveolar structure and the interaction between Cav1 and Cavin1, which however, requires ATP. ${ }^{[8]}$

\section{Involvement of caveolin-1 in cancer}

Since their discovery, there have been literally thousands of studies that have tried to address the function of caveolae and/or Cav1. Indeed, epidemiological, molecular and clinical date converge to imply caveolae and/or Cav1 in several cancer-associated processes, such as cell transformation, tumor growth, cell migration, invasion, multidrug 
resistance (MDR) and angiogenesis. The role of caveolae in cancer remains, however, debated with either beneficial or detrimental effects. ${ }^{[10]}$ The lack of specific cargo and the absence until recently of specific tools have contributed to the persisting controversies on the role of caveolae. Several studies have produced quite opposite conclusions, and there is still often confusion between caveolae as bona fide organelles and Cav1 as the protein constituting caveolae. From these studies, it is quite impossible to reach a clear consensus on the role of caveolae. Nevertheless, one should privilege recent studies where the availability of Cav1 knockout mice, the identification of new Cav1 partners and the use of genome-edited cell lines are likely to produce more specific results and hopefully resolve some of the controversies in the field.

\section{Cav1: A tumor suppressor?}

The D7S522 locus on human chromosome 7q31.1, where the Cav1 gene is localized, is commonly deleted in various human cancers, including breast, kidney, prostate, neck, ovary, and colon cancers suggesting that this region, in particular, Cav1 may be a tumor suppressor. ${ }^{[9,69]}$ Supporting this hypothesis, a sporadic negative mutant of Cav1 P132L has been described. The expression of P132L mutant results in the absence of caveolae at the plasma membrane. ${ }^{[70,71]}$ Indeed, this mutant is retained in the Golgi apparatus. This mutation is dominant negative when both the P132L mutant and wild-type Cav1 are expressed in cells, both become localized to the Golgi, which is a fate common to misfolded proteins. ${ }^{[70]}$ The P132L mutant induces cellular transformation and causes up-regulation of several signaling pathway (endothelial growth factor [EGF], hepatocyte growth factor [HGF], MAPK). ${ }^{[72]}$ Furthermore, a study demonstrates that in Met-1 cells, Cav1 P132L acts as a loss-of-function mutation and promotes recurrence of breast cancer. ${ }^{[73]}$ In human breast cancer, Hayashi et al., reported that this mutation was found in $16 \%$ of 92 samples of human breast cancers. ${ }^{[72-74]}$ Another study showed that Cav1 P132L mutation was present in $9 \%$ of breast cancers. ${ }^{[75]}$ However, the existence of this mutation has also been debated with studies reporting that the P132L mutation was not detected in breast cancer and others cancers types. ${ }^{[76,77]}$ It is interesting that a similar mutation P104L on the muscle-specific Cav3 isoform has been associated with muscular dystrophies. ${ }^{[78]}$

Many oncogenes, including Src, Ras, Bcr-Abl, have been shown to transcriptionally down-regulate Cav1 expression. Indeed, Cav1 levels are decreased in NIH-3T3 cells transformed by Bcr-Abl and Ras and inversely correlated with the soft agar growth. ${ }^{[79]}$ Reduction of Cav1 using antisense approach induces transformation in mouse embryo fibroblast cells (NIH-3T3), allowing these cells to form tumors in nude mice. ${ }^{[80]}$ The generation of $\mathrm{Cav}^{(--)}$mice supports the idea that Cav1 is a "transformation" suppressor. However, Cav $1^{(--)}$mice do not develop mammary tumors in the absence of additional genetic/carcinogenic stimuli. ${ }^{[81,82]}$ After chemical carcinogenic treatment, the skin of Cav1 $1^{(-1)}$ mice form tumors associated with cyclinD1 overexpression, ERK1/2 hyperactivation, and epidermal proliferation. ${ }^{[83,84]}$ The crossing of Cav $1^{(--)}$mice with tumor prone transgenic mice-Polyoma middle T antigen (MMTV), a breast cancer mouse model, accelerate the appearance of mammary tumors and metastatic lung disease. ${ }^{[85-87]}$ Crossing Cav $1^{(--)}$ mice with $I N K 4 \mathrm{a}^{(--)}$, a tumor suppressor, induce also the alteration of mammary epithelial ductal morphology, with hyperplasia, increased side-branching and fibrosis. ${ }^{[86,88]}$ Loss of Cav1 in the INK4a $\mathrm{a}^{(--)}$genetic background results in constitutive hyperactivation of the p42/44 MAP kinase, decreased expression of p21Cip1, as well as cyclinD1 overexpression, consistent with their hyperproliferative phenotype. Cav1 is also reduced or absent in mammary tumors from MMTV-c-Myc,-Her2,-Src,-Ha-Ras and p53 null transgenic mice. ${ }^{[89]}$

\section{Cav1: An oncogene?}

It appears that Cav1 expression may be reduced, unchanged, or overexpressed depending of the tumor cell type. Indeed, Cav1 is downregulated in ovarian, lung and mammary carcinomas, whereas Cav1 is overexpressed in the bladder, esophagus, thyroid and prostate carcinomas. ${ }^{[88]}$ Moreover, during the early stage of tumorigenesis, Cav1 inhibit cell cycle progression and cell proliferation, whereas Cav1 may induce more advanced cancer phases, including metastatic process. ${ }^{[00,91]}$

Cav1 expression could result in increased cell migration and invasion. Indeed, it was shown that Cav1 promotes Rac1 activation and migration of cancer cells. Cav1 prevents Rab5 inactivation through the endosomal recruitment of the PI3 kinase subunit $\mathrm{p} 85 \alpha$ known to increase Rab5 GTPase activity, leading to increased Rac1 activity and enhanced tumor cell migration and invasion. ${ }^{[92]}$ Cav1-induced cell migration and Rac1 activation are accompanied by increased melanoma metastasis in vivo ${ }^{\left[{ }^{[3]}\right.}$ Moreover, the RhoA/Rho-associated protein kinase signaling pathway has been shown to promote migration and invasion by regulating focal adhesion dynamics through Src-dependent Cav1 pY14. ${ }^{[94,95]}$

Different studies have shown that Cav1 is upregulated during metastasis. It was shown in the mouse that Cav1 is overexpressed in metastatic prostate cells compared with the primary prostate tumor. ${ }^{[96]}$ In breast cancer, a strong association was found between Cav1 expression and a basal-like-phenotype, since $52 \%$ of tumors that expressed Cav 1 had this phenotype, compared with only $9 \%$ of Cav1-negative carcinomas ${ }^{\left[{ }^{[9]}\right.}$ Moreover, $90 \%$ of metaplastic breast cancers have been shown to express Cav1 ${ }^{[82]}$ Cav1 overexpression 
has been also correlated with metastasis in esophageal squamous cell carcinoma, renal cell carcinoma, mammary adenocarcinoma, and metastatic cell lines derived from lung adenocarcinoma ${ }^{[94,98-100]} \mathrm{Cav} 1$ upregulation during metastasis process is therefore in favor of the oncogenic activity of Cav1.

The upregulation of Cav1 may be linked to the observation that Cav1 levels are also increased during MDR in cancer cells. ${ }^{[101,102]}$ MDR is a multifactorial process that involves the elevated expression of drug transporters as well as additional biochemical changes that contribute to the drug-resistant phenotype. Cav1 has been implicated in mediating resistance to chemotherapeutics and radiotherapy. ${ }^{[103]}$ Indeed, Cav1 expression is increased in MDR-MCF7 breast cancer cells. ${ }^{[103]}$ The consequence of the upregulation of Cav1 in MDR cells is a slower rate of proliferation, which may provide MDR cells with some protection against the action of cytotoxic drugs and thus contribute to their selective growth advantage under chemotherapy.

The role of Cav1 is clearly multidimensional, and available evidence does not allow to confidently assign Cav1 expression levels with a canonical tumor suppressor or oncogenic activities.

\section{Cav1 in the microenvironment}

Cancer development and progression is not only associated with the proliferation of tumor cells, but also with interactions within the stromal cellular microenvironment that is, represented by fibroblasts, immune and inflammatory cells. Recently, several studies have involved stromal Cav1 in tumor progression and metastasis. It has been reported that the absence of stromal Cav1 is associated with poorer prognosis and is a predictor of metastasis in breast cancer. ${ }^{[104-107]}$ Loss of stromal Cav1 predicts poor outcome in triple-negative breast cancers, ${ }^{[108]}$ whereas high stromal Cav1 correlates with reduced tumor size, grade, metastasis and improved survival. ${ }^{[109,110]}$ The loss of stromal Cav1 could promote tumor growth, via the upregulation of collagen VI and other extracellular matrix (ECM) components, in the tumor/stromal microenvironment. ${ }^{[111]}$ Likewise, stromal Cav1 was downregulated in pancreatic cancer compared with paraneoplastic and normal tissue. Loss of stromal Cav1 is closely correlated with advanced tumor stage, lymph node metastasis, distant metastasis, and poor prognosis. ${ }^{[112,113]}$

In contrast to these studies, the expression of Cav1 in cancer-associated fibroblasts (CAFs) or tumor-associated fibroblasts and in stromal cells has recently been associated with a worse outcome in breast cancer. ${ }^{[14]}$ Indeed, Cav1 expression in breast CAFs correlates with low survival, and Cav1 depletion in CAFs decreases stromal cells contractility. Consistently, CAF expression of Cav1, which occurs through p190RhoGAP activation, was required to guide the migration and invasiveness of carcinoma cells in vitro. In vivo, stromal Cav1 remodels peri-and intratumoral microenvironments to facilitate tumor invasion, correlating with increased metastatic potency. ${ }^{[114]}$ It was also observed that Cav1 is expressed in fibroblasts from the desmoplastic pancreatic cancer stroma, but not in stromal cells from normal pancreas. ${ }^{[15]}$ The reasons for this apparent discordance about the role of stromal Cav1 expression and its association with good or poor prognosis in cancer remain unknown.

\section{Cav1 and neovascularization}

Neovascularization is yet another very important contributor to tumor growth. Indeed, in the absence of neoangiogenesis, tumors would remain small and localized to their primary site. In addition, neovascularization is often associated with rheological perturbations of the blood flow in tumors and likely contributes to the increased level of mechanical forces encountered by cancer cells. Under hypoxia, tumor cells are able to secrete angiogenic factors, such as vascular endothelial growth factor (VEGF) and basic fibroblast growth factor (bFGF) that induce the tumor neovascularization. ${ }^{[116]}$ Endothelial cells which constitute the monolayer cell wall of arteries and veins are particularly enriched in caveolae, and Cav1 has been shown to control several aspects of endothelial cell functions in normal and pathological conditions. ${ }^{[117,118]}$ For instance, it was shown in Ewing sarcoma that Cav1 together with EphA2 induce the activation of AKT signaling to produce bFGF, promoting tumor-induced endothelial cell migration and favoring angiogenesis. ${ }^{[119]}$ In prostate cancer, Cav1 is also capable of significantly altering the tumor microenvironment by stimulating angiogenesis. Cav1 would stimulate specific angiogenic activities through the modulation of the PI3K-eNOS pathway. ${ }^{[120]}$ It was shown that prostate tumors positive for Cav1 displayed greater angiogenesis in comparison to the Cav1 negative prostate tumors. It was also observed that Cav1 colocalized with VEGF-2 in tumor-associated endothelial cells. ${ }^{[121]}$ Moreover, the depletion of Cav1 in endothelial cells affected cell migration and reduced angiogenesis in response to VEGF. ${ }^{[122]}$ Plasmalemmal vesicle associated protein 1 (PV1) is an endothelial specific protein with structural roles in the formation of diaphragms in various structures of endothelial cells including caveolae. PV1 is also highly expressed in endothelial cells of many solid tumors, especially after VEGF or HGF stimulation and can induce endothelial cell migration. ${ }^{[117]}$ Removal of caveolae in mice by depletion of Cav1 or Cavin1 reduced the protein level of PV1 in lung microvascular endothelial cells. ${ }^{[120]}$ However, the absence of Cavin1 in prostate cancer cells contributes significantly to tumor progression and metastasis by promoting the angiogenesis potential of prostate cancer cells. ${ }^{[123]}$ 


\section{Caveolae new partners and cancer}

During the progression of prostate cancer, a loss of Cavin1 expression was observed. ${ }^{[124,125]}$ In prostate cancer cells, down expression of Cavin1 induced cell migration and contributed significantly to tumor progression and metastasis. ${ }^{[123,126]}$ These effects are mediated through reduced expression of matrix metalloproteases and altered secretion of proteases, cytokines and growth regulatory proteins. ${ }^{[127,128]}$ Furthermore, re-expression of Cavin1 in PC 3 cells (human prostate adenocarcinoma) that have lost Cavin1 expression reduces the migratory capacity of these cells and tumor growth and metastasis in vivo. ${ }^{[126,129]}$ Similarly, Cavin1 expression is decreased in lung cancer ${ }^{[130]}$ In breast cancer, the Cavin1 expression is down-regulated as a result of methylation of the Cavin1 promoter ${ }^{[131]}$ Cavin1 play also a role in the MDR in breast cancer. ${ }^{[132]}$ Indeed, Cavin1 is necessary for MDR in cancer cells via the fortification of lipid rafts. Since Cavin1 and Cav1 are co-transcriptionally regulated, a loss of Cavin1 will be associated with a loss of Cav1 as well. Thus, it will be important to know whether these effects are directly linked to the absence of Cavin1, the associated loss of Cav1 or the resulting lack of assembled caveolae is unknown. In this context, Cavin1 was shown to modulate the oncogenic function of Cav 1 and to cooperate with Cav 1 to enhance aggressiveness. ${ }^{[133]}$ The role of Cavin1 in cancer is in agreement with the co-transcriptional regulation of Cavin1 and Cav1.

Cavin2 is also down-regulated in breast, kidney, and prostate tumors. ${ }^{[134,135]}$ Cavin2 was also associated with the ability of normal cells to control the growth of adjacent tumor cells. ${ }^{[136]}$ Cavin3 is frequently inactivated in ovarian cancers. ${ }^{[137]}$ Cavin 3 is also down-regulated in breast cancer cell lines and breast tumor tissue. ${ }^{[131]}$ Cavin 3 may repress matrix metalloproteinase- 9 transcriptional regulation and act as tumor suppressor in controlling the invasive potential of cells. ${ }^{[138]}$ It was also observed that the DNA methylation of Cavin 3 is associated with the acquisition of chemoresistance to the in colorectal cancer. ${ }^{[139]}$ The EHD2 gene is localized in the chromosome 19q-Arm glioma tumor suppressor region, but EHD2 has been previously excluded as a candidate for the glioma $19 q$ tumor suppressor gene. ${ }^{[140]}$ Moreover, EHD2 was reduced in human esophageal squamous cell carcinoma as compared to adjacent normal tissues. Under-expression of EHD2 increased the motility property of ESCC cell TE1 in vitro. ${ }^{[141]}$ Under-expression of EHD2 has also been reported in malignant serous ovarian cancer samples. ${ }^{[142]}$

\section{A new mechanical role for caveolae in cancer?}

Cells in multicellular tissues are subjected to a myriad of forces, including compressive, tensile, fluid shear stress and hydrostatic pressure, each of which plays an intricate part in the shaping, development and maintenance of the tissue. Importantly, the manner in which cells interact with these forces, and hence respond to them, is largely dictated by the physical properties of the cells, their adjacent cells and the ECM, which is the principal extracellular component of all tissues and organs. Cancer cells exist in a constantly evolving tissue microenvironment of diverse cell types within a proteinaceous ECM. As tumors evolve, the physical forces within this complex microenvironment change, with pleiotropic effects on both cell- and tissue-level behaviors. Recent studies point to the emerging concept that the mechanical microenvironment of tumors may have an important role in the control of their evolution. ${ }^{[143-145]}$

Indeed, tumors are often characterized by an enhanced rigidity of their structure in comparison to the surrounding tissue. While this aspect is well known to pathologists, it has been poorly explored at the molecular level. An elegant study has recently shown that the mechanical pressure exerted by tumor growth onto nontumours adjacent colon epithelium could actively promote malignant transformation in vivo. ${ }^{[146]}$ It has been shown in breast cancer cell lines that the degree of tumor rigidity and fibrosis may influence the first stage of cancer leading to the invasive stage when cells metastasize to other parts of the organism ${ }^{[147]}$ and fibrotic "stiff" lesions have a poor prognosis. ${ }^{[148]}$ In a recent work examining tissue rigidity and tumor behavior, matrix stiffness could be directly related to tissue growth and was suggested to be a key factor in tumorogenesis. ${ }^{[149]}$ It was further shown that tumor rigidity reflected an increase in stromal stiffness and tumor cell tension, and that these two processes were linked through Rho and growth factor dependent ERK activation, and involved integrins. ${ }^{[150]}$

In situ biomechanical characterization of mouse mammary gland with atomic force microscopy revealed that mammary tissues stiffness increases as they transformed and that the epithelium, tumor-associated vasculature and the ECM each contribute to the mechanical landscape of the evolving tumor. ${ }^{[151]}$ Importantly, isolated tumor cells also show an intrinsic higher membrane tension value than their normal counterparts. ${ }^{[149]}$ In this context, it is interesting that the expression of Cav1 in epithelial and stromal cells (adipocytes, fat pads, fibroblasts) provides a protective effect against mammary tumorigenesis. ${ }^{[111]}$ In contrast, another study shows that stromal Cav1 remodels peri- and intra-tumoral microenvironments in vivo to facilitate tumor invasion, correlating with increased metastatic potency. ${ }^{[14]}$ The fact that the expression of Cav1 in human cancer cell lines and tumor samples seems to depend on tumor type and stage may explain these apparent contradictions. ${ }^{[152]}$ Thus, the role of Cav1 in tumorigenesis would clearly depend on the stage of the tumor with a tumor suppressor role in nonneoplasic tissues, a loss of expression during transformation 
and a re-expression in advanced tumor stages (metastases and MDR). ${ }^{[153]}$ If this model corroborates with most animal models and patients data, the molecular mechanisms controlling Cav1 levels with respect to tumor evolution are unknown.

During tumor evolution, cancer cells are likely to experience different types of mechanical constraints during their contact with the different tissue microenvironments [Figure 1]. ${ }^{[145]}$ In carcinoma in situ, the loss of cell polarity and increased cell proliferation result in volume expansion and mechanical resistance from the basal membrane and interstitial ECM, which leads to increased forces between cancer cells and stromal matrix. ECM components remodeling leads also to increased ECM and tissue stiffness, and thereby increased cell tension. In invasive tumors, cancer cells breakdown the basal membrane and invade the ECM, again experiencing different degrees of forces from the density of the ECM network. These forces together with genetic and epigenetic events can modify the contractility and viscoelasticity of cancer cells. During intravasation and extravasation, cancer cells again experience various forces, especially shear forces from the blood flow. Finally, when cancer cells metastasize, they are likely to encounter very different mechanical surroundings, according to the stiffness or softness of the invaded organ.

Based on our recent discovery that caveolae play a key role in the adaptation of cells to mechanical stress, ${ }^{[11]}$ we propose the new hypothesis that the mechano-dependent cycle of caveolae disassembly/reassembly, and its molecular consequences on mechanosignaling and Cav1 synthesis,

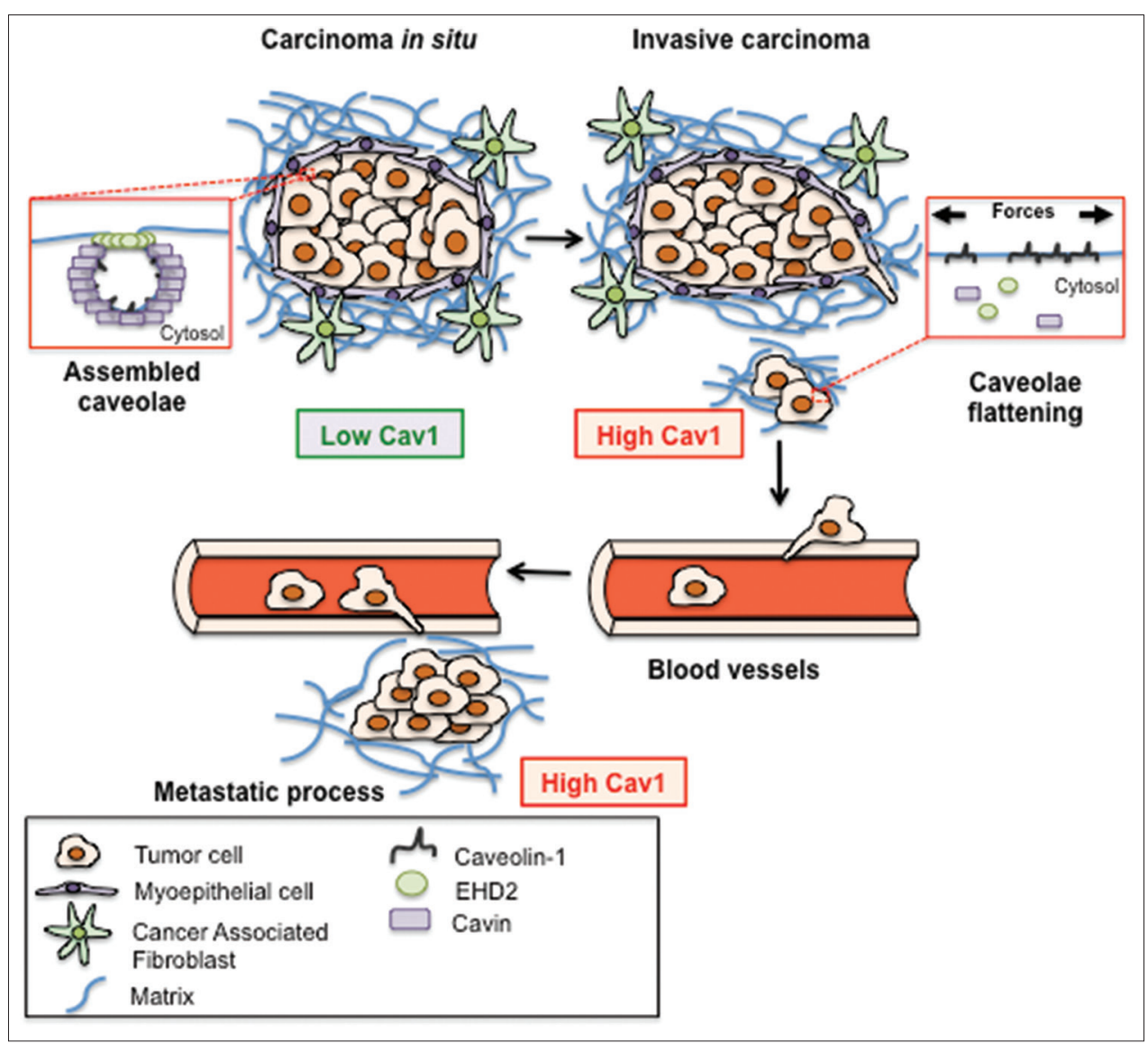

Figure 1: Potential role of caveolae in tumor progression. Tumors are often characterized by enhanced rigidity and stiffness and recent evidence shows that tumor progression is associated with alterations in tissue and cell mechanics. Caveolin 1 (Cav1), the main constituent of caveolae, is clearly involved in tumor progression. A biphasic expression pattern could be correlated with distinct Cav1 functions. It was shown that Cav1 expression is low during the first stage of tumor progression, however, Cav1 is overexpressed during the advanced cancer phases, including metastatic process. Thus, Cav1 would act as a tumor suppressor at early stage of transformation and tumor progression while it would play an oncogenic role inducing migration and metastasis at later stages. Our hypothesis is that the dual role of Cav1 in tumor progression may be explained by their recently discovered new function as mechanosensors that adapt the cell response to mechanical forces. Thus, in in situ carcinoma, when proliferative tumor cells become confined by the basal membrane, functional caveolae respond as mechanosensors with cycles of caveolae disassembly/reassembly induced by external forces. In invasive carcinoma, tumor cells break down the basal membrane and invade the extracellular matrix. Tumor cells are thus exposed to mechanical forces generated by the extracellular matrix and tissue stiffness. Increased mechanical environment may overwhelm and alter the functional cycle of caveolae disassembly/reassembly. This in turn may impair the caveolae mechanical response and Cav1 dependent mechano-signaling thereby promoting migration and metastasis formation. 
determines, at least in part, the role of caveolae in tumor progression. Caveolae mechanics are likely to be impaired in cellular microenvironments with increased membrane tension and rigidity such as those experienced by cancer and stroma cells during tumor mass progression. In support of this hypothesis, Cavin-1, -2 and -3 , which are required to assemble functional caveolae at the plasma membrane are down-regulated in breast cancer cell lines and breast tumor tissues. ${ }^{[154]}$

As mentioned above, an unresolved question in the field is to know whether distinct functions are carried out by free Cav1 that is, noncaveolar Cav1 and by caveolar Cav1 that is, assembled Cav1 in functional caveolae. In this context, it is important to note that mechanical constraints may be one of the physiologically relevant stimuli resulting in the release of free Cav1 at the plasma membrane. Indeed, total internal reflection fluorescence-fluorescence recovery after photobleaching microscopy used in the Sinha study revealed a three-fold increase of diffusing free Cav1 at the plasma membrane under hypo-osmotic shock. This is likely due to the mechanical disassembly of the caveolae structure after its flattening. Conversely, removal of the mechanical force led to caveolae reassembly and to a reduction of the amount of free Cav1 at the plasma membrane presumably through the reincorporation of free Cav1 into newly assembled caveolae. ${ }^{[11]}$ It is therefore tempting to speculate that the ON/OFF cycle of caveolae disassembly/reassembly induced by mechanical stress will have an impact on the activation/inactivation cycle of signaling molecules associated with caveolae either through direct binding to Cav1, or through the release of caveolar constituents from the plasma membrane to other intracellular destinations. ${ }^{[8]}$ It is also possible that the Cav1 CSD may be differently accessible to CBM-containing signaling molecules whether Cav1 is assembled into a budded caveolae or is diffusing freely at the plasma membrane. Thus, there would be a dynamic competition between Cav1 CSD for caveolae assembly (i.e. CSD interacting with Cav1 CSD) and signaling effectors (i.e. interacting with CBM-signaling effectors). Variations of the mechanical landscape measured in tumor and stroma cells may alter this regulation in a stage-dependent manner. We propose that the dual role of caveolae and Cav1 in cancer may be related to this new concept. ${ }^{[8]}$ At early stages of tumor progression, mechanical forces encountered by cancer and stromal cells would be minimal and functional caveolae would be able to respond to these forces by flattening out and by releasing free Cav1 in the plasma membrane, which would activate anti-tumoral or inhibit pro-tumoral signaling effectors. At later stages, increased stiffness, the membrane tension, and mechanical forces would overwhelm the capacity of caveolae to respond which in turn would activate pro-tumoral or inhibit anti-tumoral signaling effectors. Mutations such as the Cav1 P132L mutation described above $^{[72-74]}$ or abnormal levels of Cav1 and Cav1 partners expression such as cavins ${ }^{[154]}$ could also lead to impaired caveolar mechanical responses in tumors. We believe this hypothesis provides a possible explanation to the apparent dual role of caveolae in tumor progression by linking the stage of tumor evolution with the mechanical environment and the mechanosignaling response by caveolae.

\section{Conclusion}

Cav1, a key structural component of caveolae, is clearly involved in tumor progression. Whether this is Cav1 expression or Cav1 loss that is, critical for tumor progression remains debated. The answer may be more complex than just Cav1 expression levels. Indeed, a biphasic expression pattern was observed with Cav1 acting as a tumor suppressor at an early stage of transformation and tumor progression, whereas the oncogenic activity of Cav1 could induce migration and metastasis at later stages. This notion of two opposite roles for the same protein, depending on the stage of tumor progression, has been already described. For instance, transforming growth factor-beta (TGF- $\beta$ ), a prominent player in cell differentiation and proliferation, has been shown to either promote or suppress tumorigenesis depending on the tumor developmental stage. ${ }^{[155]}$ Since caveolae have been associated with the regulation of TGF- $\beta$ signaling, ${ }^{[156]}$ it will be important to investigate whether this regulation depends on the mechanical stage of the tumor. An array of recent evidence indicates that studies on caveolae in cancer should be replaced in the context of the latest findings on the mechanical role of caveolae. ${ }^{[1]]}$ It will be therefore important to investigate the involvement of the mechano-dependent cycle of caveolae disassembly/reassembly, and its consequences on the mechanosignaling pathways involved in tumor progression for different types of cancers.

\section{Acknowledgments}

This work was supported by Agence Nationale de la Recherche (ANR-12-BSV2-0011 and ANR-14CE09-0008-03), Association Française des Myopathies, and Institut National du Cancer (INCa AAP PLBIO 2012) grants. Stéphanie Torrino is supported by ARC foundation postdoctoral fellowship. This work has been done by a team belonging to the labex CelTisPhyBio 11-LBX-0038. We wish to thank Weiwei Shen and Cédric Blouin for carefully reading the manuscript and Maria Daniela Garcia Castillo for help with editing.

\section{Financial support and sponsorship}

Nil. 


\section{Conflicts of interest}

There are no conflicts of interest.

\section{REFERENCES}

1. Palade GE. The fine structure of blood capillaries. J Appl Phys $1953 ; 24: 1424$

2. Glenney JR Jr. Tyrosine phosphorylation of a $22-\mathrm{kDa}$ protein is correlated with transformation by Rous sarcoma virus. J Biol Chem 1989;264:20163-6.

3. Glenney JR Jr, Zokas L. Novel tyrosine kinase substrates from Rous sarcoma virus-transformed cells are present in the membrane skeleton. J Cell Biol 1989;108:2401-8.

4. Glenney JR Jr, Soppet D. Sequence and expression of caveolin, a protein component of caveolae plasma membrane domains phosphorylated on tyrosine in Rous sarcoma virus-transformed fibroblasts. Proc Natl Acad Sci USA 1992;89:10517-21.

5. Kurzchalia TV, Dupree P, Parton RG, Kellner R, Virta H, Lehnert M, et al. VIP21, a 21-kD membrane protein is an integral component of trans-Golgi-network-derived transport vesicles. J Cell Biol 1992;118:1003-14.

6. Fridolfsson HN, Roth DM, Insel PA, Patel HH. Regulation of intracellular signaling and function by caveolin. FASEB J 2014;28:3823-31.

7. Patel HH, Murray F, Insel PA. Caveolae as organizers of pharmacologically relevant signal transduction molecules. Annu Rev Pharmacol Toxicol 2008;48:359-91.

8. Nassoy P, Lamaze C. Stressing caveolae new role in cell mechanics. Trends Cell Biol 2012;22:381-9.

9. Engelman JA, Zhang XL, Galbiati F, Lisanti MP. Chromosomal localization, genomic organization, and developmental expression of the murine caveolin gene family (Cav-1, -2 , and -3 ). Cav-1 and Cav-2 genes map to a known tumor suppressor locus (6-A2/7q31). FEBS Lett 1998;429:330-6.

10. Goetz JG, Lajoie P, Wiseman SM, Nabi IR. Caveolin-1 in tumor progression: The good, the bad and the ugly. Cancer Metastasis Rev 2008;27:715-35.

11. Sinha B, Köster D, Ruez R, Gonnord P, Bastiani M, Abankwa D, et al. Cells respond to mechanical stress by rapid disassembly of caveolae. Cell 2011;144:402-13.

12. Rothberg KG, Heuser JE, Donzell WC, Ying YS, Glenney JR, Anderson RG. Caveolin, a protein component of caveolae membrane coats. Cell 1992;68:673-82.

13. Murata M, Peränen J, Schreiner R, Wieland F, Kurzchalia TV, Simons K. VIP21/caveolin is a cholesterol-binding protein. Proc Natl Acad Sci USA 1995;92:10339-43.

14. Monier S, Dietzen DJ, Hastings WR, Lublin DM, Kurzchalia TV. Oligomerization of VIP21-caveolin in vitro is stabilized by long chain fatty acylation or cholesterol. FEBS Lett 1996;388:143-9.

15. Pelkmans L, Zerial M. Kinase-regulated quantal assemblies and kiss-and-run recycling of caveolae. Nature 2005;436:128-33.

16. Ludwig A, Howard G, Mendoza-Topaz C, Deerinck T, Mackey M, Sandin S, et al. Molecular composition and ultrastructure of the caveolar coat complex. PLoS Biol 2013;11:e1001640.

17. Gambin Y, Ariotti N, McMahon KA, Bastiani M, Sierecki E,
Kovtun O, et al. Single-molecule analysis reveals self assembly and nnoscale segregation of two distinct cavin subcomplexes on caveolae. Elife 2013;3:e01434.

18. Kovtun O, Tillu VA, Jung W, Leneva N, Ariotti N, Chaudhary N, et al. Structural insights into the organization of the cavin membrane coat complex. Dev Cell 2014;31:405-19.

19. Khan EM, Heidinger JM, Levy M, Lisanti MP, Ravid T, Goldkorn T. Epidermal growth factor receptor exposed to oxidative stress undergoes Src- and caveolin-1-dependent perinuclear trafficking. J Biol Chem 2006;281:14486-93.

20. Li S, Seitz R, Lisanti MP. Phosphorylation of caveolin by src tyrosine kinases. The alpha-isoform of caveolin is selectively phosphorylated by v-Src in vivo. J Biol Chem 1996;271:3863-8.

21. Schlegel A, Arvan P, Lisanti MP. Caveolin-1 binding to endoplasmic reticulum membranes and entry into the regulated secretory pathway are regulated by serine phosphorylation. Protein sorting at the level of the endoplasmic reticulum. J Biol Chem 2001;276:4398-408.

22. Garver WS, Hossain GS, Winscott MM, Heidenreich RA. The Npc1 mutation causes an altered expression of caveolin-1, annexin II and protein kinases and phosphorylation of caveolin-1 and annexin II in murine livers. Biochim Biophys Acta 1999;1453:193-206.

23. Fielding PE, Chau P, Liu D, Spencer TA, Fielding CJ. Mechanism of platelet-derived growth factor-dependent caveolin-1 phosphorylation: Relationship to sterol binding and the role of serine- 80 . Biochemistry 2004;43:2578-86.

24. Trane AE, Pavlov D, Sharma A, Saqib U, Lau K, van Petegem F, et al. Deciphering the binding of caveolin-1 to client protein endothelial nitric-oxide synthase (eNOS): Scaffolding subdomain identification, interaction modeling, and biological significance. J Biol Chem 2014;289:13273-83.

25. Jasmin JF, Mercier I, Sotgia F, Lisanti MP. SOCS proteins and caveolin-1 as negative regulators of endocrine signaling. Trends Endocrinol Metab 2006;17:150-8.

26. Byrne DP, Dart C, Rigden DJ. Evaluating caveolin interactions: Do proteins interact with the caveolin scaffolding domain through a widespread aromatic residue-rich motif? PLoS One 2012;7:e44879.

27. Collins BM, Davis MJ, Hancock JF, Parton RG. Structure-based reassessment of the caveolin signaling model: Do caveolae regulate signaling through caveolin-protein interactions? Dev Cell 2012;23:11-20.

28. Bernatchez P, Sharma A, Bauer PM, Marin E, Sessa WC A noninhibitory mutant of the caveolin-1 scaffolding domain enhances eNOS-derived NO synthesis and vasodilation in mice. J Clin Invest 2011;121:3747-55.

29. Lajoie P, Nabi IR. Lipid rafts, caveolae, and their endocytosis. Int Rev Cell Mol Biol 2010;282:135-63.

30. Stahlhut M, van Deurs B. Identification of filamin as a novel ligand for caveolin-1: Evidence for the organization of caveolin-1-associated membrane domains by the actin cytoskeleton. Mol Biol Cell 2000;11:325-37.

31. Hansen CG, Howard G, Nichols BJ. Pacsin 2 is recruited to caveolae and functions in caveolar biogenesis. J Cell Sci 2011;124(Pt 16):2777-85.

32. Drab M, Verkade P, Elger M, Kasper M, Lohn M, Lauterbach B, et al. Loss of caveolae, vascular dysfunction, and pulmonary defects in caveolin-1 gene-disrupted mice. Science 2001;293:2449-52.

33. Bastiani M, Liu L, Hill MM, Jedrychowski MP, Nixon SJ, Lo HP, et al. MURC/Cavin-4 and cavin family members form tissue-specific 
caveolar complexes. J Cell Biol 2009;185:1259-73.

34. Parton RG, del Pozo MA. Caveolae as plasma membrane sensors, protectors and organizers. Nat Rev Mol Cell Biol 2013;14:98-112.

35. Hansen CG, Nichols BJ. Exploring the caves: Cavins, caveolins and caveolae. Trends Cell Biol 2010;20:177-86.

36. Jansa P, Burek C, Sander EE, Grummt I. The transcript release factor PTRF augments ribosomal gene transcription by facilitating reinitiation of RNA polymerase I. Nucleic Acids Res 2001;29:423-9.

37. Liu L, Pilch PF. A critical role of cavin (polymerase I and transcript release factor) in caveolae formation and organization. J Biol Chem 2008;283:4314-22.

38. Hill MM, Bastiani M, Luetterforst R, Kirkham M, Kirkham A, Nixon SJ, et al. PTRF-Cavin, a conserved cytoplasmic protein required for caveola formation and function. Cell 2008;132:113-24.

39. Burgener R, Wolf M, Ganz T, Baggiolini M. Purification and characterization of a major phosphatidylserine-binding phosphoprotein from human platelets. Biochem J 1990;269:729-34.

40. Gustincich S, Vatta P, Goruppi S, Wolf M, Saccone S, Della Valle G, et al. The human serum deprivation response gene (SDPR) maps to $2 \mathrm{q} 32-\mathrm{q} 33$ and codes for a phosphatidylserine-binding protein. Genomics 1999;57:120-9.

41. Mineo C, Ying YS, Chapline C, Jaken S, Anderson RG. Targeting of protein kinase Calpha to caveolae. J Cell Biol 1998;141:601-10.

42. Hansen CG, Bright NA, Howard G, Nichols BJ. SDPR induces membrane curvature and functions in the formation of caveolae. Nat Cell Biol 2009;11:807-14.

43. Izumi Y, Hirai Si, Tamai Y, Fujise-Matsuoka A, Nishimura Y, Ohno S. A protein kinase Cdelta-binding protein SRBC whose expression is induced by serum starvation. J Biol Chem 1997;272:7381-9.

44. Xu XL, Wu LC, Du F, Davis A, Peyton M, Tomizawa Y, et al. Inactivation of human SRBC, located within the 11p15.5-p15.4 tumor suppressor region, in breast and lung cancers. Cancer Res 2001;61:7943-9.

45. McMahon KA, Zajicek H, Li WP, Peyton MJ, Minna JD, Hernandez VJ, et al. SRBC/cavin-3 is a caveolin adapter protein that regulates caveolae function. EMBO J 2009;28:1001-15.

46. Ogata T, Ueyama T, Isodono K, Tagawa M, Takehara N, Kawashima T, et al. MURC, a muscle-restricted coiled-coil protein that modulates the Rho/ROCK pathway, induces cardiac dysfunction and conduction disturbance. Mol Cell Biol 2008;28:3424-36.

47. Tagawa M, Ueyama T, Ogata T, Takehara N, Nakajima N, Isodono K, et al. MURC, a muscle-restricted coiled-coil protein, is involved in the regulation of skeletal myogenesis. Am J Physiol Cell Physiol 2008;295:C490-8

48. Rodriguez G, Ueyama T, Ogata T, Czernuszewicz G, Tan Y, Dorn GW $2^{\text {nd }}$, et al. Molecular genetic and functional characterization implicate muscle-restricted coiled-coil gene (MURC) as a causal gene for familial dilated cardiomyopathy. Circ Cardiovasc Genet 2011;4:349-58.

49. Ogata T, Naito D, Nakanishi N, Hayashi YK, Taniguchi T, Miyagawa K, et al. MURC/Cavin-4 facilitates recruitment of ERK to caveolae and concentric cardiac hypertrophy induced by a1-adrenergic receptors. Proc Natl Acad Sci USA 2014;111:3811-6.

50. Shvets E, Ludwig A, Nichols BJ. News from the caves: Update on the structure and function of caveolae. Curr Opin Cell Biol 2014;29:99-106.
51. Morén B, Shah C, Howes MT, Schieber NL, McMahon HT, Parton RG, et al. EHD2 regulates caveolar dynamics via ATP-driven targeting and oligomerization. Mol Biol Cell 2012;23:1316-29.

52. Stoeber M, Stoeck IK, Hänni C, Bleck CK, Balistreri G, Helenius A. Oligomers of the ATPase EHD2 confine caveolae to the plasma membrane through association with actin. EMBO J 2012;31:2350-64.

53. Oh P, McIntosh DP, Schnitzer JE. Dynamin at the neck of caveolae mediates their budding to form transport vesicles by GTP-driven fission from the plasma membrane of endothelium. J Cell Biol 1998;141:101-14.

54. Richter T, Floetenmeyer M, Ferguson C, Galea J, Goh J, Lindsay MR, et al. High-resolution 3D quantitative analysis of caveolar ultrastructure and caveola-cytoskeleton interactions. Traffic 2008;9:893-909.

55. Wickström SA, Lange A, Hess MW, Polleux J, Spatz JP, Krüger M, et al. Integrin-linked kinase controls microtubule dynamics required for plasma membrane targeting of caveolae. Dev Cell 2010;19:574-88

56. Nixon SJ, Carter A, Wegner J, Ferguson C, Floetenmeyer M, Riches J, et al. Caveolin-1 is required for lateral line neuromast and notochord development. J Cell Sci 2007;120(Pt 13):2151-61.

57. Simons K, Toomre D. Lipid rafts and signal transduction. Nat Rev Mol Cell Biol 2000;1:31-9.

58. Parton RG, Simons K. The multiple faces of caveolae. Nat Rev Mol Cell Biol 2007;8:185-94.

59. Pilch PF, Liu L. Fat caves: Caveolae, lipid trafficking and lipid metabolism in adipocytes. Trends Endocrinol Metab 2011;22:318-24.

60. Kim CA, Delépine M, Boutet E, El Mourabit H, Le Lay S, Meier M, et al. Association of a homozygous nonsense caveolin-1 mutation with Berardinelli-Seip congenital lipodystrophy. J Clin Endocrinol Metab 2008;93:1129-34.

61. Li WP, Liu P, Pilcher BK, Anderson RG. Cell-specific targeting of caveolin-1 to caveolae, secretory vesicles, cytoplasm or mitochondria. J Cell Sci 2001;114(Pt 7):1397-408.

62. Gaus K, Le Lay S, Balasubramanian N, Schwartz MA Integrin-mediated adhesion regulates membrane order. J Cell Biol 2006;174:725-34.

63. Goetz JG, Joshi B, Lajoie P, Strugnell SS, Scudamore T, Kojic LD, et al. Concerted regulation of focal adhesion dynamics by galectin-3 and tyrosine-phosphorylated caveolin-1. J Cell Biol 2008;180:1261-75.

64. Hill MM, Scherbakov N, Schiefermeier N, Baran J, Hancock JF, Huber LA, et al. Reassessing the role of phosphocaveolin-1 in cell adhesion and migration. Traffic 2007;8:1695-705.

65. Zheng YZ, Boscher C, Inder KL, Fairbank M, Loo D, Hill MM, et al. Differential impact of caveolae and caveolin-1 scaffolds on the membrane raft proteome. Mol Cell Proteomics 2011;10:M110.007146.

66. Lajoie P, Kojic LD, Nim S, Li L, Dennis JW, Nabi IR. Caveolin-1 regulation of dynamin-dependent, raft-mediated endocytosis of cholera toxin-B sub-unit occurs independently of caveolae. J Cell Mol Med 2009;13:3218-25.

67. Chaudhary N, Gomez GA, Howes MT, Lo HP, McMahon KA, Rae JA, et al. Endocytic crosstalk: Cavins, caveolins, and caveolae regulate clathrin-independent endocytosis. PLoS Biol 2014;12:e1001832.

68. Pietuch A, Brückner BR, Janshoff A. Membrane tension homeostasis of epithelial cells through surface area regulation in response to 
osmotic stress. Biochim Biophys Acta 2013;1833:712-22.

69. Engelman JA, Zhang XL, Lisanti MP. Genes encoding human caveolin-1 and -2 are co-localized to the D7S522 locus (7q31.1), a known fragile site (FRA7G) that is frequently deleted in human cancers. FEBS Lett 1998;436:403-10.

70. Lee H, Park DS, Razani B, Russell RG, Pestell RG, Lisanti MP. Caveolin-1 mutations (P132L and null) and the pathogenesis of breast cancer: Caveolin-1 (P132L) behaves in a dominant-negative manner and caveolin-1 (-/-) null mice show mammary epithelial cell hyperplasia. Am J Pathol 2002;161:1357-69.

71. Rieth MD, Lee J, Glover KJ. Probing the caveolin-1 P132L mutant: Critical insights into its oligomeric behavior and structure. Biochemistry 2012;51:3911-8.

72. Hayashi K, Matsuda S, Machida K, Yamamoto T, Fukuda Y, Nimura $\mathrm{Y}$, et al. Invasion activating caveolin-1 mutation in human scirrhous breast cancers. Cancer Res 2001;61:2361-4.

73. Bonuccelli G, Casimiro MC, Sotgia F, Wang C, Liu M, Katiyar S, et al. Caveolin-1 (P132L), a common breast cancer mutation, confers mammary cell invasiveness and defines a novel stem cell/ metastasis-associated gene signature. Am J Pathol 2009;174:1650-62.

74. Bouras T, Lisanti MP, Pestell RG. Caveolin-1 in breast cancer. Cancer Biol Ther 2004;3:931-41.

75. Li T, Sotgia F, Vuolo MA, Li M, Yang WC, Pestell RG, et al. Caveolin-1 mutations in human breast cancer: Functional association with estrogen receptor alpha-positive status. Am J Pathol 2006;168:1998-2013.

76. Chen ST, Lin SY, Yeh KT, Kuo SJ, Chan WL, Chu YP, et al. Mutational, epigenetic and expressional analyses of caveolin-1 gene in breast cancers. Int J Mol Med 2004;14:577-82.

77. Koike S, Kodera Y, Nakao A, Iwata H, Yatabe Y. Absence of the caveolin-1 P132L mutation in cancers of the breast and other organs. J Mol Diagn 2010;12:712-7.

78. Carozzi AJ, Roy S, Morrow IC, Pol A, Wyse B, Clyde-Smith J, et al. Inhibition of lipid raft-dependent signaling by a dystrophy-associated mutant of caveolin-3. J Biol Chem 2002;277:17944-9.

79. Koleske AJ, Baltimore D, Lisanti MP. Reduction of caveolin and caveolae in oncogenically transformed cells. Proc Natl Acad Sci USA 1995;92:1381-5.

80. Galbiati F, Volonte D, Engelman JA, Watanabe G, Burk R, Pestell RG, et al. Targeted downregulation of caveolin-1 is sufficient to drive cell transformation and hyperactivate the p42/44 MAP kinase cascade. EMBO J 1998;17:6633-48.

81. Le Lay S, Kurzchalia TV. Getting rid of caveolins: Phenotypes of caveolin-deficient animals. Biochim Biophys Acta 2005;1746:322-33.

82. Patani N, Martin LA, Reis-Filho JS, Dowsett M. The role of caveolin-1 in human breast cancer. Breast Cancer Res Treat 2012;131:1-15.

83. Capozza F, Williams TM, Schubert W, McClain S, Bouzahzah B, Sotgia F, et al. Absence of caveolin-1 sensitizes mouse skin to carcinogen-induced epidermal hyperplasia and tumor formation. Am J Pathol 2003;162:2029-39.

84. Trimmer C, Sotgia F, Lisanti MP, Capozza F. Cav1 inhibits benign skin tumor development in a two-stage carcinogenesis model by suppressing epidermal proliferation. Am J Transl Res 2013;5:80-91.

85. Williams TM, Cheung MW, Park DS, Razani B, Cohen AW, Muller WJ, et al. Loss of caveolin-1 gene expression accelerates the development of dysplastic mammary lesions in tumor-prone transgenic mice. Mol Biol Cell 2003;14:1027-42.

86. Williams TM, Lee H, Cheung MW, Cohen AW, Razani B, Iyengar $\mathrm{P}$, et al. Combined loss of INK4a and caveolin-1 synergistically enhances cell proliferation and oncogene-induced tumorigenesis: Role of INK4a/CAV-1 in mammary epithelial cell hyperplasia. J Biol Chem 2004;279:24745-56.

87. Sloan EK, Stanley KL, Anderson RL. Caveolin-1 inhibits breast cancer growth and metastasis. Oncogene 2004;23:7893-7.

88. Williams TM, Lisanti MP. Caveolin-1 in oncogenic transformation, cancer, and metastasis. Am J Physiol Cell Physiol 2005;288:C494-506.

89. Razandi M, Oh P, Pedram A, Schnitzer J, Levin ER. ERs associate with and regulate the production of caveolin: Implications for signaling and cellular actions. Mol Endocrinol 2002;16:100-15.

90. Li L, Yang G, Ebara S, Satoh T, Nasu Y, Timme TL, et al. Caveolin-1 mediates testosterone-stimulated survival/clonal growth and promotes metastatic activities in prostate cancer cells. Cancer Res 2001;61:4386-92.

91. Tahir SA, Yang G, Ebara S, Timme TL, Satoh T, Li L, et al. Secreted caveolin-1 stimulates cell survival/clonal growth and contributes to metastasis in androgen-insensitive prostate cancer. Cancer Res 2001;61:3882-5.

92. Díaz J, Mendoza P, Ortiz R, Díaz N, Leyton L, Stupack D, et al. Rab5 is required in metastatic cancer cells for Caveolin-1-enhanced Rac1 activation, migration and invasion. J Cell Sci 2014;127(Pt 11):2401-6.

93. Lobos-González L, Aguilar L, Diaz J, Diaz N, Urra H, Torres VA, et al. E-cadherin determines Caveolin-1 tumor suppression or metastasis enhancing function in melanoma cells. Pigment Cell Melanoma Res 2013;26:555-70.

94. Nestl A, Von Stein OD, Zatloukal K, Thies WG, Herrlich P, Hofmann M, et al. Gene expression patterns associated with the metastatic phenotype in rodent and human tumors. Cancer Res 2001;61:1569-77.

95. Joshi B, Strugnell SS, Goetz JG, Kojic LD, Cox ME, Griffith OL, et al. Phosphorylated caveolin-1 regulates Rho/ROCK-dependent focal adhesion dynamics and tumor cell migration and invasion. Cancer Res 2008;68:8210-20.

96. Yang G, Truong LD, Timme TL, Ren C, Wheeler TM, Park SH, et al. Elevated expression of caveolin is associated with prostate and breast cancer. Clin Cancer Res 1998;4:1873-80.

97. Pinilla SM, Honrado E, Hardisson D, Benítez J, Palacios J. Caveolin-1 expression is associated with a basal-like phenotype in sporadic and hereditary breast cancer. Breast Cancer Res Treat 2006;99:85-90.

98. Joo HJ, Oh DK, Kim YS, Lee KB, Kim SJ. Increased expression of caveolin-1 and microvessel density correlates with metastasis and poor prognosis in clear cell renal cell carcinoma. BJU Int 2004;93:291-6.

99. Ho CC, Huang PH, Huang HY, Chen YH, Yang PC, Hsu SM. Up-regulated caveolin-1 accentuates the metastasis capability of lung adenocarcinoma by inducing filopodia formation. Am J Pathol 2002;161:1647-56.

100. Kato K, Hida Y, Miyamoto M, Hashida H, Shinohara T, Itoh T, et al. Overexpression of caveolin-1 in esophageal squamous cell carcinoma correlates with lymph node metastasis and pathologic stage. Cancer 2002;94:929-33.

101. Bélanger MM, Gaudreau M, Roussel E, Couet J. Role of caveolin-1 in etoposide resistance development in A549 lung cancer cells. Cancer Biol Ther 2004;3:954-9. 
102. Quest AF, Gutierrez-Pajares JL, Torres VA. Caveolin-1: An ambiguous partner in cell signalling and cancer. J Cell Mol Med 2008; 12:1130-50.

103. Lavie Y, Fiucci G, Liscovitch M. Up-regulation of caveolae and caveolar constituents in multidrug-resistant cancer cells. J Biol Chem 1998;273:32380-3.

104. Martinez-Outschoorn UE, Whitaker-Menezes D, Pavlides S, Chiavarina B, Bonuccelli G, Casey T, et al. The autophagic tumor stroma model of cancer or "battery-operated tumor growth": A simple solution to the autophagy paradox. Cell Cycle 2010;9:4297-306.

105. Witkiewicz AK, Dasgupta A, Nguyen KH, Liu C, Kovatich AJ, Schwartz GF, et al. Stromal caveolin-1 levels predict early DCIS progression to invasive breast cancer. Cancer Biol Ther 2009;8:1071-9.

106. Witkiewicz AK, Dasgupta A, Sotgia F, Mercier I, Pestell RG, Sabel M, et al. An absence of stromal caveolin-1 expression predicts early tumor recurrence and poor clinical outcome in human breast cancers. Am J Pathol 2009;174:2023-34.

107. Senetta R, Stella G, Pozzi E, Sturli N, Massi D, Cassoni P. Caveolin-1 as a promoter of tumour spreading: When, how, where and why. J Cell Mol Med 2013;17:325-36.

108. Witkiewicz AK, Dasgupta A, Sammons S, Er O, Potoczek MB, Guiles F, et al. Loss of stromal caveolin-1 expression predicts poor clinical outcome in triple negative and basal-like breast cancers. Cancer Biol Ther 2010;10:135-43.

109. Martins D, Beça FF, Sousa B, Baltazar F, Paredes J, Schmitt F. Loss of caveolin-1 and gain of MCT4 expression in the tumor stroma: Key events in the progression from an in situ to an invasive breast carcinoma. Cell Cycle 2013;12:2684-90.

110. Sotgia F, Martinez-Outschoorn UE, Howell A, Pestell RG, Pavlides S, Lisanti MP. Caveolin-1 and cancer metabolism in the tumor microenvironment: Markers, models, and mechanisms. Annu Rev Pathol 2012;7:423-67.

111. Trimmer C, Sotgia F, Whitaker-Menezes D, Balliet RM, Eaton G, Martinez-Outschoorn UE, et al. Caveolin-1 and mitochondrial SOD2 (MnSOD) function as tumor suppressors in the stromal microenvironment: A new genetically tractable model for human cancer associated fibroblasts. Cancer Biol Ther 2011;11:383-94.

112. Shan T, Lu H, Ji H, Li Y, Guo J, Chen X, et al. Loss of stromal caveolin-1 expression: A novel tumor microenvironment biomarker that can predict poor clinical outcomes for pancreatic cancer. PLoS One 2014;9:e97239.

113. Sloan EK, Ciocca DR, Pouliot N, Natoli A, Restall C, Henderson MA, et al. Stromal cell expression of caveolin-1 predicts outcome in breast cancer. Am J Pathol 2009;174:2035-43.

114. Goetz JG, Minguet S, Navarro-Lérida I, Lazcano JJ, Samaniego R, Calvo E, et al. Biomechanical remodeling of the microenvironment by stromal caveolin-1 favors tumor invasion and metastasis. Cell 2011;146:148-63.

115. Witkiewicz AK, Nguyen KH, Dasgupta A, Kennedy EP, Yeo CJ, Lisanti MP, et al. Co-expression of fatty acid synthase and caveolin-1 in pancreatic ductal adenocarcinoma: Implications for tumor progression and clinical outcome. Cell Cycle 2008;7:3021-5.

116. Carver LA, Schnitzer JE. Caveolae: Mining little caves for new cancer targets. Nat Rev Cancer 2003;3:571-81.

117. Stan RV. Endothelial stomatal and fenestral diaphragms in normal vessels and angiogenesis. J Cell Mol Med 2007;11:621-43.
118. Pavlides S, Gutierrez-Pajares JL, Danilo C, Lisanti MP, Frank PG. Atherosclerosis, caveolae and caveolin-1. Adv Exp Med Biol 2012;729:127-44.

119. Sáinz-Jaspeado M, Huertas-Martinez J, Lagares-Tena L, Martin Liberal J, Mateo-Lozano S, de Alava E, et al. EphA2-induced angiogenesis in ewing sarcoma cells works through bFGF production and is dependent on caveolin-1. PLoS One 2013;8:e71449.

120. Tkachenko E, Tse D, Sideleva O, Deharvengt SJ, Luciano MR, Xu Y, et al. Caveolae, fenestrae and transendothelial channels retain PV1 on the surface of endothelial cells. PLoS One 2012;7:e32655.

121. Thompson TC, Tahir SA, Li L, Watanabe M, Naruishi K, Yang G, et al. The role of caveolin-1 in prostate cancer: Clinical implications. Prostate Cancer Prostatic Dis 2010;13:6-11.

122. Madaro L, Antonangeli F, Favia A, Esposito B, Biamonte F, Bouché M, et al. Knock down of caveolin-1 affects morphological and functional hallmarks of human endothelial cells. J Cell Biochem 2013;114:1843-51.

123. Nassar ZD, Moon H, Duong T, Neo L, Hill MM, Francois M, et al. PTRF/Cavin-1 decreases prostate cancer angiogenesis and lymphangiogenesis. Oncotarget 2013;4:1844-55.

124. Gould ML, Williams G, Nicholson HD. Changes in caveolae, caveolin, and polymerase 1 and transcript release factor (PTRF) expression in prostate cancer progression. Prostate 2010;70:1609-21.

125. Low JY, Nicholson HD. Emerging role of polymerase-1 and transcript release factor (PTRF/Cavin-1) in health and disease. Cell Tissue Res 2014;357:505-13.

126. Hill MM, Daud NH, Aung CS, Loo D, Martin S, Murphy S, et al. Co-regulation of cell polarization and migration by caveolar proteins PTRF/Cavin-1 and caveolin-1. PLoS One 2012;7:e43041.

127. Aung CS, Hill MM, Bastiani M, Parton RG, Parat MO. PTRF-cavin-1 expression decreases the migration of $\mathrm{PC} 3$ prostate cancer cells: Role of matrix metalloprotease 9. Eur J Cell Biol 2011;90:136-42.

128. Inder KL, Zheng YZ, Davis MJ, Moon H, Loo D, Nguyen H, et al. Expression of PTRF in PC-3 Cells modulates cholesterol dynamics and the actin cytoskeleton impacting secretion pathways. Mol Cell Proteomics 2012;11:M111.012245.

129. Moon H, Lee CS, Inder KL, Sharma S, Choi E, Black DM, et al. PTRF/cavin-1 neutralizes non-caveolar caveolin-1 microdomains in prostate cancer. Oncogene 2014;33:3561-70.

130. Gámez-Pozo A, Sánchez-Navarro I, Calvo E, Agulló-Ortuño MT, López-Vacas R, Díaz E, et al. PTRF/cavin-1 and MIF proteins are identified as non-small cell lung cancer biomarkers by label-free proteomics. PLoS One 2012;7:e33752.

131. Bai L, Deng X, Li Q, Wang M, An W, Deli A, et al. Down-regulation of the cavin family proteins in breast cancer. J Cell Biochem $2012 ; 113: 322-8$

132. Yi JS, Mun DG, Lee H, Park JS, Lee JW, Lee JS, et al. PTRF/cavin-1 is essential for multidrug resistance in cancer cells. J Proteome Res $2013 ; 12: 605-14$

133. Liu L, Xu HX, Wang WQ, Wu CT, Chen T, Qin Y, et al. Cavin-1 is essential for the tumor-promoting effect of caveolin-1 and enhances its prognostic potency in pancreatic cancer. Oncogene 2014;33:2728-36.

134. Altintas DM, Allioli N, Decaussin M, de Bernard S, Ruffion A, Samarut J, et al. Differentially expressed androgen-regulated genes in androgen-sensitive tissues reveal potential biomarkers of early prostate cancer. PLoS One 2013;8:e66278. 
135. Li X, Jia Z, Shen Y, Ichikawa H, Jarvik J, Nagele RG, et al. Coordinate suppression of Sdpr and Fhll expression in tumors of the breast, kidney, and prostate. Cancer Sci 2008;99:1326-33.

136. Alexander DB, Ichikawa H, Bechberger JF, Valiunas V, Ohki M, Naus CC, et al. Normal cells control the growth of neighboring transformed cells independent of gap junctional communication and SRC activity. Cancer Res 2004;64:1347-58.

137. Tong SY, Ki KD, Lee JM, Kang MJ, Ha TK, Chung SI, et al. Frequent inactivation of hSRBC in ovarian cancers by promoter $\mathrm{CpG}$ island hypermethylation. Acta Obstet Gynecol Scand 2010;89:629-35.

138. Toufaily C, Charfi C, Annabi B, Annabi B. A role for the Cavin-3/ Matrix Metalloproteinase- 9 signaling axis in the regulation of PMA-activated human HT1080 fibrosarcoma cell neoplastic phenotype. cancer growth metastasis 2014;7:43-51.

139. Moutinho C, Martinez-Cardús A, Santos C, Navarro-Pérez V, Martínez-Balibrea E, Musulen E, et al. Epigenetic inactivation of the BRCA1 interactor SRBC and resistance to oxaliplatin in colorectal cancer. J Natl Cancer Inst 2014;106:djt322.

140. Pohl U, Smith JS, Tachibana I, Ueki K, Lee HK, Ramaswamy S, et al. EHD2, EHD3, and EHD4 encode novel members of a highly conserved family of EH domain-containing proteins. Genomics 2000;63:255-62.

141. Li M, Yang X, Zhang J, Shi H, Hang Q, Huang X, et al. Effects of EHD2 interference on migration of esophageal squamous cell carcinoma. Med Oncol 2013;30:396.

142. Bignotti E, Tassi RA, Calza S, Ravaggi A, Romani C, Rossi E, et al. Differential gene expression profiles between tumor biopsies and short-term primary cultures of ovarian serous carcinomas: Identification of novel molecular biomarkers for early diagnosis and therapy. Gynecol Oncol 2006;103:405-16.

143. DuFort CC, Paszek MJ, Weaver VM. Balancing forces: Architectural control of mechanotransduction. Nat Rev Mol Cell Biol $2011 ; 12: 308-19$.

144. Egeblad M, Rasch MG, Weaver VM. Dynamic interplay between the collagen scaffold and tumor evolution. Curr Opin Cell Biol 2010;22:697-706

145. Yu H, Mouw JK, Weaver VM. Forcing form and function: Biomechanical regulation of tumor evolution. Trends Cell Biol 2011;21:47-56.

146. Fernández-Sánchez ME, Barbier S, Whitehead J, Béalle G, Michel A, Latorre-Ossa $\mathrm{H}$, et al. Mechanical induction of the tumorigenic ß-catenin pathway by tumour growth pressure. Nature 2015 .

147. Akiri G, Sabo E, Dafni H, Vadasz Z, Kartvelishvily Y, Gan N, et al. Lysyl oxidase-related protein-1 promotes tumor fibrosis and tumor progression in vivo. Cancer Res 2003;63:1657-66.

148. Colpaert C, Vermeulen P, van Beest P, Goovaerts G, Weyler J, Van Dam P, et al. Intratumoral hypoxia resulting in the presence of a fibrotic focus is an independent predictor of early distant relapse in lymph node-negative breast cancer patients. Histopathology 2001;39:416-25.

149. Paszek MJ, Zahir N, Johnson KR, Lakins JN, Rozenberg GI, Gefen A, et al. Tensional homeostasis and the malignant phenotype. Cancer Cell 2005;8:241-54.

150. Levental KR, Yu H, Kass L, Lakins JN, Egeblad M, Erler JT, et al. Matrix crosslinking forces tumor progression by enhancing integrin signaling. Cell 2009;139:891-906.

151. Lopez JI, Kang I, You WK, McDonald DM, Weaver VM. In situ force mapping of mammary gland transformation. Integr Biol (Camb) 2011;3:910-21

152. Burgermeister E, Liscovitch M, Röcken C, Schmid RM, Ebert MP. Caveats of caveolin-1 in cancer progression. Cancer Lett 2008;268:187-201

153. Liscovitch M, Burgermeister E, Jain N, Ravid D, Shatz M, Tencer L. Caveolin and cancer: A complex relationship. In: Mattson M, editor. Membrane Microdomain Signaling Lipid Rafts in Biology and Medicine. Totowa, NJ: Human Press; 2005. p. 161-90.

154. Bai L, Deng X, Li Q, Wang M, An W, Deli A, et al. Down-regulation of the cavin family proteins in breast cancer. J Cell Biochem 2012;113:322-8

155. Morrison CD, Parvani JG, Schiemann WP. The relevance of the TGF-ß Paradox to EMT-MET programs. Cancer Lett 2013;341:30-40.

156. Del Galdo F, Lisanti MP, Jimenez SA. Caveolin-1, transforming growth factor-beta receptor internalization, and the pathogenesis of systemic sclerosis. Curr Opin Rheumatol 2008;20:713-9.

This is an open access article distributed under the terms of the Creative Commons Attribution-NonCommercial-ShareAlike 3.0 License, which allows others to remix, tweak, and build upon the work non-commercially, as long as the author is credited and the new creations are licensed under the identical term.

For reprints contact: reprints@medknow.com 